\title{
Nano Catalysts: A Newfangled Gem in the Catalytic World
}

\author{
Ashu Chaudhary* and Anshul Singh \\ Department of Chemistry, Kurukshetra University, India
}

Submission: October 30, 2017; Published: November 22, 2017

*Corresponding author: Ashu Chaudhary, Department of Chemistry, Kurukshetra University, Kurukshetra, Haryana, Pin: 136119, India,

Tel: 9729864551; Email: ashuchaudhary21@gmail.com

\begin{abstract}
Nanotechnology is no more new to the chemical world however everyday development in this field has made it the buzz word of the decade. Its all-embracing impact on more than one discipline has turned it to be a shining star in the eyes of chemists. One of the most noteworthy application of nanotechnology is in field of catalysis. Nanocatalysts have emerged out with substantial characteristics concerning selectivity, activity, lifetime and recoverability. Nanocatalysts are found to be much more effectual and profitable as large part of catalytic atoms is available to the reactants thereby increasing its efficiency manifold as compared to conventional catalysts. The present article is just an overview encompassing the introduction of nanocatalysts with dimensions affecting their catalytic performance (Figure 1).
\end{abstract}

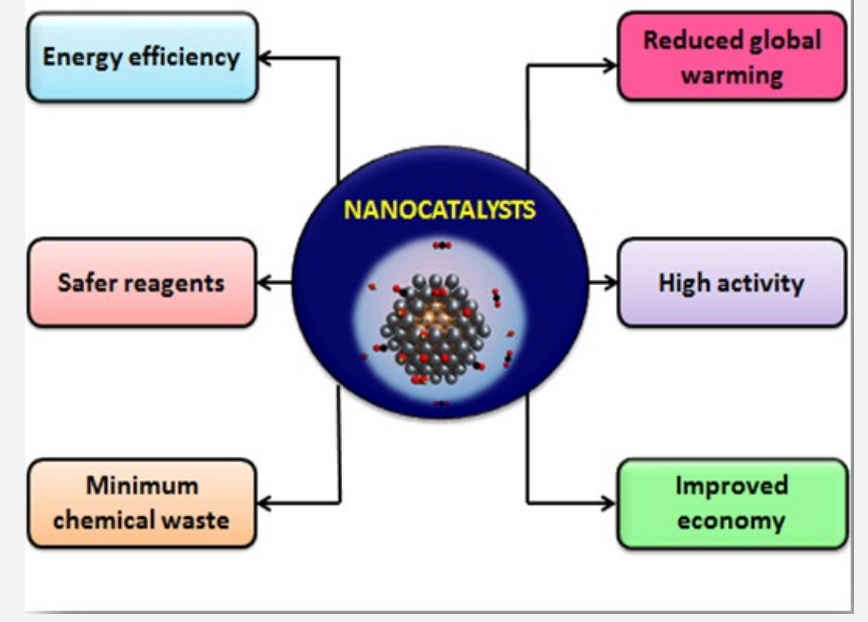

Figure 1: Graphical abstract.

Keywords: Nanotechnology; Nanocatalysts; Homogenous and heterogenous catalysis

\section{Introduction}

Nanoscience is one of the most influential technology area of the $21^{\text {st }}$ century. Due to the inimitable properties of nanoengineered materials, they are seen to have a giant potential in several areas, such as food packaging, pathogen detection, targeted drug delivery, blood purification, production of antibacterial textiles etc. Nanotechnology has aroused as a burgeoning area taking on loftier significance all over the world. The precise manipulation and control of matter at dimensions of (1-100) nanometers have revolutionized many industries making it a subject of growing interest [1].

Enormous varieties of nanoparticles have emerged in our everyday life, in field from drugs and electronics to paints and beauty care. One of the most imperative application of nanoparticles is related with catalysis. The nanoparticles of numerous materials display amazing properties, allowing them to be used as the catalysts [2]. Currently, application of 


\section{Recent Advances in Petrochemical Science}

the catalysts in the form of nanoparticles or their colloidal solutions is at the pivotal point as a result good proportion of newfangled possibilities has been unwrapped in the field of chemical synthesis [3].

In terms of chemistry, catalyst is defined as a substance that causes or accelerates a chemical reaction without itself being affected and this process is known as catalysis. A catalyst can make a reaction go faster and in more selective manner. It means that the catalyst enters the reaction and makes some changes in chemical reaction but remains without changes. Even though the catalyst has lower weight than the raw materials, it is the heart of reaction and an appropriate selection of the catalyst for a reaction is very important. Nanoparticles have accomplished many challenges as catalysts by having active sites with a core of metal atoms, metal ions and making holes around the sites. It is predicted that the next generation of catalysts are nanocatalysts which are involved in many of the chemical processes. The present article exemplifies the new generation of catalyst, named nanocatalyst.

\section{Elementary Features of Catalysts}

The most basic characteristics for a catalyst are:

a) The catalyst just augments the reaction (Figure 2) while it remains as such without any changes.

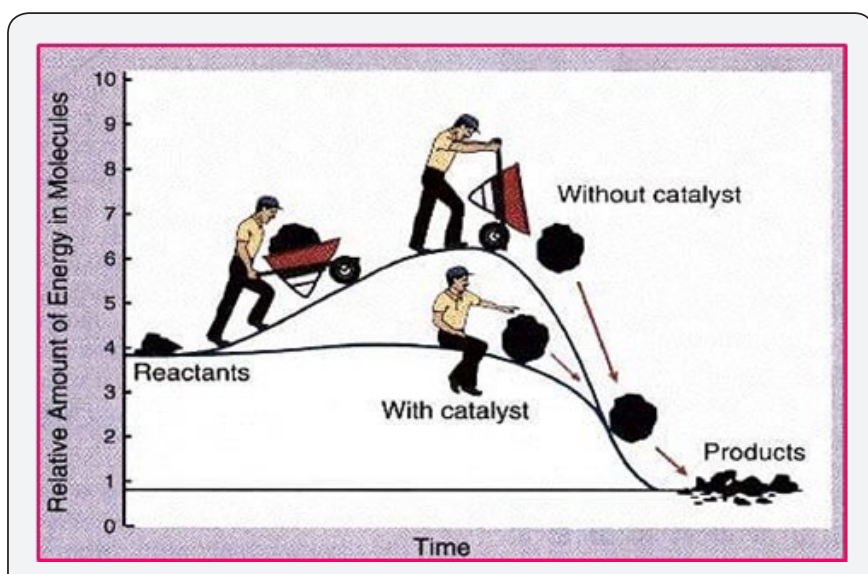

Figure 2: Diagram representing catalyst lowering the activation energy thereby accelerating the reaction.

b) A reaction can be carried out by different mechanism but the catalyst should be highly selective thereby escalating the production level of desirable material.

c) In a reversible reaction, the catalyst effects on both reactions. So the system equilibrium percentage should remain unaltered with or without catalyst [4].

\section{Advent of Nanocatalysts}

Nanocatalysis is an expeditiously mounting field which encompasses the use of nanomaterials as catalysts for a variety of homogeneous and heterogeneous catalysis applications. Since nanoparticles have a large surface-to-volume ratio paralleled to bulk materials, they are striking candidates for use as catalysts (Figure 3). Nanocatalysis amalgamates the beneficial features of both homogenous and heterogeneous catalysis, however decreasing their respective shortcomings [5].

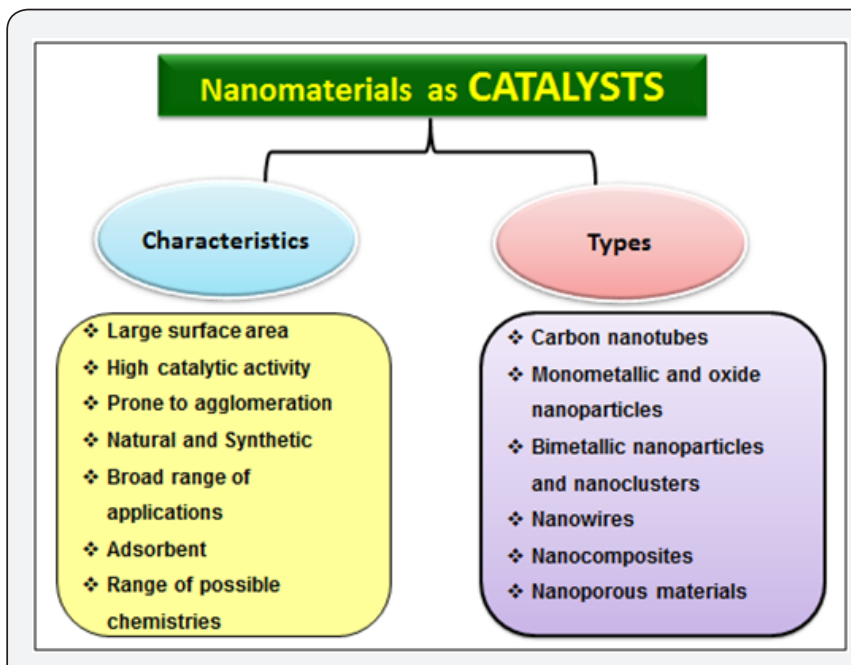

Figure 3: Diagram signifying types and features of nanocatalysts.

a) In homogeneous catalysis, the initial materials and the catalytic substance are brought together in the similar phase, which confirms great catalytic activity and selectivity [6]. However, the practical application of homogeneous catalysis is restricted by the complications to isolate the catalyst from the product after completion of the reaction [7].

b) In heterogeneous catalysis, the initial materials and the catalytic substance exist in different phases [8], thereby assuaging the separation of products and catalyst. However a major disadvantage of traditional heterogeneous catalyst systems when equated to their homogeneous counterparts is the curtailed surface area that is available to reactant molecules, thus restraining their catalytic activities [9] and leading to a superfluously high consumption of exclusive catalyst materials [10]. However this problem can be sorted out by increasing the surface to volume ratio $(\mathrm{S} / \mathrm{V})$ thus reducing the size of the catalytically active material $[11,12]$.

\section{Dimensions for Catalytic Performance of a Nanocatalyst}

The most significant objective of nanocatalysis research is to generate catalysts with maximum selectivity, enormously great activity, low energy consumption, and protracted lifetime. A nanocatalyst is considered to be preeminent if it exhibits superior performance in the ensuing dimensions:
a. Selectivity,
b. Activity,
c. Durability and
d. Recoverability 
a) A catalyst should be highly selective producing $100 \%$ of the product despite the fact that the reaction pathway would result into thermodynamically stable molecules. In this way, a wearisome separation step can be removed thereby converting raw material into the product more proficiently [1].

b) The number of reactant molecules converted into product per unit time by the catalyst is expressed by the activity of catalyst which is measured using turnover frequency (TOF). As compared to homogenous catalytic systems which exhibits appropriately TOF in the range of $0.3 \mathrm{~s}-1$ or higher, nanocatalytic systems are targeted to attain much higher TOF making it more promising for industrial applications.

c) The catalyst with high durability permits the profitable production of large amount of the product before the system could be interrupted for the catalytic replacement. The durability or lifetime of a catalyst can be measured in terms of turnover number (TON), which is actually expressed as the total amount of product (in moles) that can be formed by a given amount (in moles) of catalyst [13].

d) The foremost intrusion to the commercial application of a lot of promising homogeneous catalytic systems is the recoverability of the catalytically active substance. Hence, an optimal nanocatalyst features an intrinsic system enabling its separation from the reaction mixture and its reuse after termination of the reaction.

\section{Factors Affecting Catalytic Activity of Nano-catalyst}

The four dimensions revealed overhead are intensely influenced by following parameters:

a. Size of catalyst

b. Geometry of catalyst

c. Surface functionality

d. Surface composition

e. Aggregation attitude

f. Physical environment and

g. Chemical environment

\section{Conclusion}

Nanocatalysts are part of upcoming cutting edge technology. The field of nano catalysis has endured a rapid growth during the past decade, both in homogeneous and heterogeneous catalysis. Nano particles have a large surfaceto-volume ratio as equated to bulk materials; hence they are striking materials to be used as catalysts. Nanomaterials offer many possibilities as catalysts to meet future global demands in the following catalytic process technology:
a) Petroleum refining
b) Petrochemical industry

c) Synthetic fuel production

d) Polymer manufacturing

e) Pharmaceutical sector

f) Food processing and

g) Chemical sector

Research in nanotechnology and nanoscience is expected to have a great impact on the development of new catalysts. The present article is just an overview of the nanocatalysts which are illustrated as an approach towards green chemistry contributing with lower energy consumption, longer lifetime and high selectivity. The diligent understanding of nanosized substances and the capacity to control materials on the nanometer scale will confirm a rational and cost effective expansion of new and more capable catalysts for a chemical process.

\section{Acknowledgement}

The authors (Ashu Chaudhary and Anshul Singh) wish to express gratitude to the Council of Scientific and Industrial Research (CSIR), New Delhi, India for financial assistance in the form of SRF vide letter no. 09/105(0221)/2015-EMR-I.

\section{References}

1. Olveira S, Forster SP, Seeger S (2014) Nanocatalysis: Academic Discipline and Industrial Realities. Journal of Nanotechnology 2014: 1-19.

2. Fatullayeva SS, Vakhshouri AR, Zergerova SH (2017) Industrial application of Nanocatalysts. Processes of Petro chemistry and oil Refining 18(1): 49-61.

3. Heiz U, Landman U (2007) Nanocatalysis (NanoScience and Technology) ( $1^{\text {st }}$ edn), Springer, Verlag Berlin Heidelberg, New york, USA, p. 504.

4. Dehkordi MG (2016) The role and use of catalysts and nano-catalysts in the refining industry. Journal of Fundamental \& Applied Sciences 8(2S): 916-927.

5. Polshettiwar V, Varma RS (2010) Green chemistry by nanocatalysis. Green Chemistry 12(5): 743-754.

6. Behr A, Neubert P (2012) Applied Homogeneous Catalysis. ( $1^{\text {st }}$ edn $)$, Wiley-VCH, Weinheim, Germany, pp. 1-716.

7. Hamilton CDJ (2003) Homogeneous catalysis-new approaches to catalyst separation, recovery, and recycling. Science 299(5613): 17021706.

8. Jacoby M (2009) Perfecting solid-catalyst synthesis. Chemical \& Engineering News 87(17): 37-38.

9. Zach M, Hagglund C, Chakarov D, Kasemo B (2006) Nanoscience and nanotechnology for advanced energy systems. Current Opinion in Solid State and Materials Science 10(3-4): 132-143.

10. Zahmakiran M, Ozkar S (2011) Metal nanoparticles in liquid phase catalysis: from recent advances to future goals. Nanoscale 3(9): 34623481.

11. Campelo JM, Luna D, Luque R, Marinas JM, Romero AA, et al. (2009) Sustainable preparation of supported metal nanoparticles and their applications in catalysis. Chem Sus Chem 2(1): 18-45. 
12. Teunissen W, Bol AA, Geus JW (1999) Magnetic catalyst bodies. Catalysis Today 48(1-4): 329-336.

13. Yan N, Xiao C, Kou Y (2010) Transition metal nanoparticle catalysis in green solvents: novel and smart materials: design, synthesis, structure, properties and applications. In celebration of the centennial anniversary of chemical research and education at Peking University. Coordination Chemistry Reviews 254(9-10): 939-1218.

Your next submission with Juniper Publishers will reach you the below assets

- Quality Editorial service

- Swift Peer Review

- Reprints availability

- E-prints Service

- Manuscript Podcast for convenient understanding

- Global attainment for your research

- Manuscript accessibility in different formats

( Pdf, E-pub, Full Text, Audio)

- Unceasing customer service

Track the below URL for one-step submission https://juniperpublishers.com/online-submission.php 